\title{
HOW USEFUL ARE THE EPISTEMIC STRUCTURES OF 'CAPABILITIES' AND 'AFRIKOLOGY' IN ADDRESSING SOCIAL JUSTICE IN AFRICA?
}

\author{
Ronald Elly Wanda \\ Grundtvig Africa House Mt Kenya University, Kenya
}

\begin{abstract}
In the crowded argumentative space of political philosophies, it is often alleged that Justice is the highest goal of political life. Yet for most folks in Africa it is injustice instead that continues to dominate political debate. This article uses the epistemology of Afrikology to advance the African cultural understanding of "equality" to argue that this is a crucial tenet in appreciating the interpretation that African communities give to the concept of justice and the subsequent social dislocation that can be found in the use of Amartya Kumar Sen's Capabilities approach (1980; 1984; 1985; 1987; 1992; 1999) on the continent. Neo-liberal's 'personal jurisdiction' particularity as universality is challenged throughout the explorative epistemological discussion between Capabilities and an emerging Afrikology $(2011$; 2012) position offered through the restorative scholarship of celebrated East African scholar Dani Wadada Nabudere.
\end{abstract}

Keywords: Capabilities; Afrikology; Culture; Epistemology and Social Justice. 


\section{Introduction}

There is a general agreement in the crowded argumentative space of political philosophies that justice is the highest goal of political life. Yet for most communities in Africa it is injustice that instead continues to dominate the political debate. Furthermore, the linkage and interface between democracy and social justice in the continent remains such a heated subject. As such, questioning what constitutes social justice in contemporary societies in Africa is important, but even more so is the need to focus on how people perceive issues of social justice and injustice. One could indeed ask, as has Vivienne Taylor, is aspiring towards social justice a pipe dream because the contextual realities are so far removed from the vision that imbued struggles for liberation from political, economic, social, and cultural domination? Does the shadow of collective histories weigh so heavily that one cannot work towards achieving freedoms from forms of neo-colonialism and political and social domination? And has the promise of hard won liberation and national independence come to naught in contemporary Africa? (Taylor, 2012: 12). Better still, one may further ask, could a discourse on social justice catalyze assertions of the right to bring back social, community-wide concerns for development based on justice and sustainability into our contemporary struggles?

Injustice in Africa is as such an intuitive subject to start an explorative epistemological discussion on the Nobel laureate Indian economist Amartya Sen's influential Capabilities framework (Sen, 1980; 1984; 1985; 1987; 1992; 1999) together with an emerging restorative scholarship offered in renowned east African scholar Dani Nabudere's Afrikology $(2011 ; 2012)$ epistemology. Specifically opposed to neo-liberal's 'personal jurisdiction' particularity as universality, this article uses the artillery of Afrikology to advance the African cultural understanding of "equality". We argue that this is a crucial tenet in appreciating the interpretation that African communities give to the concept of justice and the subsequent cultural dislocation that can be found in the use of Sen's Capabilities approach on the continent. We have found that although a large number of scholars and policy-makers (Nussbaum, 2000, 2003, 2006, 2008; Clark, 2008; Stark, 2009; Claassen, 2011; Qizibashi, 2013 etc) have engaged with Sen's ideas; virtually none have done so from the epistemological basis of Afrikology.

\section{The Imperial Narrative}

Since gaining political independence in the early 1960s, theories of political and social development have been presented to Africa as 'scientific' theories extracted from their social and historical conditions, implying that they represent 
the only valid paradigm that cannot be criticized or refuted. According to Egyptian scholar Nasr Arif, these theories have received such widespread popularity that even the UN, as we shall see of Sen's Capabilities framework later, adopts them as its international blueprint for the so called developing countries. A critical and close reading of these theories, however, reveals that they are nothing but a set of ideological premises that reflect the Western experience. One common characteristic of these theories is to generalize their results to the entire world by eliminating their own specific characteristics and the historical conditions that underlie them (Arif, 2002: 1).

Professor Arif further contends that the net result of these theoryconstructions for the 'developing world' is to declare it as underdeveloped, stagnant, irrational and reactionist. On the basis of these assumptions, they replace the traditional culture, value norms, and patterns of behavior by the Western value system. Therefore, any discussion of development, whether social, political or economic; entails an implicit, if not explicit, Western perspective on civilization, modernity and value systems. Arif claims that the ultimate goal of this set of theories is not to elevate the world, develop it economically, and raise the standards of living in various parts of the world as underdeveloped, make it dependent on western resources, and finally create a market from which the West can buy raw materials and to which it can then sell the end product which is, in turn, manufactured by the cheap labor power of this market (Arif, 2002: 2). The Egyptian scholar further warns that "there is no more effective way guaranteeing the dependency of the nonwestern world than convincing it that the western model of development is the only possible and valid path. This model is to be seen as a moving goal, and the more the poor countries try to attain it, the wider the gap between them and the West grows" (Arif, 2002: 2).

\section{Afrikology}

In Africa, Nabudere was well aware of Hartley Dean and Ruth Rodgers observation that "human society is axiomatically to be understood as an association of interdependent beings. And yet dependency in late-modern societies has become problematic" (Dean and Rodgers, 2004). In his epistemological work on Afrikology, Nabudere's philosophy persistently, and consistently, made proposals for a different moral approach to addressing, and possibly solving, some of the root causes of human conflicts across the world. He took suffering seriously as the basis of his idea of a global-level collective justice which, for him, raised the idea of 'alienation' and the ethics of community care to the level of global justice. The exemplary paradox of his works is that it sought to know tradition and understand its grounds on the one 
hand and yet to strengthen it at the same time; it was necessary to know it in order to understand it, it would seem. He was convinced that indigenous knowledge systems were more realistic in treating nature as a transcendent reality with reverence and awe. Indigenous ways of living and knowing, according to Nabudere, were also useful in teaching about the crucial distinction between frugal subsistence and poverty. Agreeably, Swedish scholar Catherine Hoppers, an expert on indigenous knowledge systems, has observed elsewhere that "modernity has plenty to learn from African traditions" (Hoppers, 2008: 84).

In his 1997 article Writing and Oral tradition in the Transmission of Knowledge writer Doussou F. C. described the word indigenous as the root, something natural or innate (to). It is related to being an integral part of culture. By indigenous knowledge systems are meant the combination of knowledge systems encompassing technology, philosophy, social, economic, learning/educational, legal and governance systems. It is about the technologies such as looms, textile, jewellery and brass-work manufacture; and about technological knowledge in agriculture, fishing, forest resource exploitation, atmospheric management techniques, knowledge transmission systems (Doussou 1997: 309), architecture, medicine and pharmacology.

The Beninese philosopher Paulin Hountondji has added that these knowledge are rich and varied, ranging from soil and plant taxonomy, cultural and genetic information, animal and crop husbandry, medicine and pharmacology, ecology, climatology, zoology, music, arts, architecture, and many others (Hountondji, 1997). Their intrinsic efficiency and efficacy as tools for personal, societal and global development must therefore be identified and accredited as necessary. Professor Hountondji further contends that it is this recovery of indigenous knowledge, and the systems intricately woven around them that will enable the move towards a critical but resolute re-appropriation of the practical and cognitive heritage of millions of people around the continent and elsewhere in the world. It is, in turn, the re-appropriation of this heritage that may provide new clues and directions as to the visions of human society, human relations, sustainable development, poverty reduction and scientific development in the next millennium, all of which cannot be resolved using the existing ethos of the Western framework alone (Hountondji, 1997: 39).

Indeed, the first articulation of Afrikology declares that: "it is a true philosophy of knowledge and wisdom based on African cosmogonies. It is Afri- because it is inspired by the ideas originally produced from the Cradle of Humankind located in Africa. It is not Afrikology because it is African, but it is Afri-because it emanates 
from the source of the Universal system of knowledge originating in Africa. The philosophic product is therefore not relativistic to Africa but universal in essence with its base in Africa. It is also - (ko) logy because it is based on the logos-the word, which was uttered to set in motion the Universe in its originality. It was from that word that human consciousness first emerged and it was from that consciousness that humanity emerged as thinking and acting agent with language from the word as the active cultural achievement (Wanda, 2013:2).

As such, the epistemological knowledge of Afrikology, according to Nabudere, flows directly from the need for Africans to redefine their world, which can enable them to advance their self-understanding and the world around them based on African cosmologies. "The issue of creating knowledge that promotes African self-understanding and a knowledge that can promote their transformation is not just an issue of methodologies" (Nabudere, 2011:36). Nabudere has explained that the objective of imperialism was to capture the upper ground of knowing the natives in order to control their thinking and self-understanding. The objective was to reduce them to something "other" than them "self," or the masters. Many of the academic disciplines were especially created to understand the natives for that purpose. In Afrikology: Philosophy and Wholeness (2011), one of his last books before his sudden death in November of the same year, he illustrated:

Afrikology is not African-centric or Afrocentric. It is a universal scientific epistemology that goes beyond Eurocentricism, or other ethnocentrisms. It recognises all sources of knowledge as valid within their historical, cultural or social contexts and seeks to engage them into a dialogue that can lead to better knowledge for all. It recognises peoples' traditions as a fundamental pillar in the creation of such cross-cultural understandings in which the Africans can stand out as having been the fore-bearers of much of what is called Greek or European heritage as fact of history that ought to be recognised, because from this fact alone, it can be shown that cross-cultural interactions has been a fact of historical reality (Nabudere, 2011: 92).

Afrikology draws its scientificity and uniqueness from the fact that it is based on an all-embracing philosophy of humankind originating in Egypt and updated by the lived experiences of all humanity, who still continue to draw on its deep-rooted wisdom. It is based on a philosophy that is conscious of itself, conscious of its own existence as thought. 
Trusting on the criticality and intentionality of Afrikology's hermeneutics, we begin our discussion on Sen's Capabilities framework with none other than John Rawls. Over the years, there have been several attempts, most notably the welfarist and resourcist approaches among others that have endeavored to explain and redress poverty, violence and social injustices in Africa. The welfarist approach was unsatisfactory because it gave unreliable answers as to how peoples' satisfaction with their lives was measured. The rejection of the welfarist approach is similarly to be found in Marxist theories of exploitation, relating social judgments to the historical information that capital represents the product of past labour (Atkinson, 1998). As for the resourcist approach associated with the American political philosopher John Rawls' 1971 classic A Theory of Justice including those that went beyond Gross National Product (GNP) and looked at how much resources individuals had available to them, failed to take into account the fact that resources were not valuable in themselves, but only insofar as they enabled a person to function in certain ways. The resourcist approach was also not meant to tell us who was badly off in terms of either capabilities or welfare.

\section{John Rawls - A Theory of Justice}

Moreover, according to Rawls' position, 'justice' in a democratic society is said to refer in theory to two principles, which must primarily apply to "the basic structure of society" (Rawls, 1971: 259). The first of these principles is that each person must have an equal right to the most extensive basic liberty compatible with a similar liberty for others. The second principle of Rawls principles is that social and economic inequalities are to be arranged in such a way that they are both (a) reasonably expected to be to everyone's advantage, and (b) generally attached to public or private positions and offices open to all. These two principles are said to govern the assignment of rights and duties and to regulate the distribution of social and economic advantages. They presuppose that the social structure of society can be divided into two or less distinct parts with related principles, the first principle applying to the one, the second to the other, and thereby distinguishing between those aspects of the social system that define and secure the equal liberties of citizenship and those that specify and establish social and economic inequalities:

The basic liberties of citizens are, roughly speaking, political liberty (the right to vote and be eligible for public office) together with freedom of speech and assembly, liberty of conscience and freedom of thought; freedom of the person along with the right to hold (personal) property; and freedom from arbitrary arrest and seizure as defined by the concept of the rule of law. These liberties are all required to 
be equal by the first principle, since citizens of a just society are to have the same basic rights (Rawls, 1971: 6061).

But as Nabudere cogently ponders, which kind of 'person' is Rawls referring to and in what kind of society does he/she live in? Nabudere thinks this is important especially in the context of an illiberal society that has been dominated by dictatorships or a regime of violence where the rule of law is consistently violated such as the case maybe in Africa. In such a situation, how can justice as defined by Rawls be realised yet without such a realisation, justice cannot be claimed to have been achieved? This, according to Nabudere, remains a dilemma for John Rawls' theory of justice since the social and economic system under which he is examining this dichotomy does not address the need to have a holistic approach to their realization (Nabudere, 2012: 6).

\section{Development as Freedom}

John Rawls' liberal resourcist insight has played a significant role in shaping Sen's Capabilities framework as attested by Sen's 1973 proposition for a "weak equity axiom". Rawls has as such, been a constant reference for Sen both in overcoming welfarism and in considering 'impartiality'. Although in his initial build up Sen's alternative welfarism became distinctively different to Rawls's liberal approach that was aimed at spelling out the normative principles of a just and democratic government, along with at least the outlines of an institutional and policy framework within which such political power should be exercised.

Professor Mozaffar Qizilbash has pointed out that the capabilities framework first developed in 1980 by Amartya Sen in his Tanner Lecture Equality of What? has been an ongoing development, refined throughout the years until its final maturity in Sen's later work published in 1999 as Development as Freedom and The Idea of Justice that followed ten years later in 2009. Over the years, other variations of the approach have also emerged. In particular, feminist philosopher Martha Nussbaum's version of the approach, that contains a distinct view in moral and political theory (Qizilbash 2013: 35).

In Development as Freedom Sen argued that development in all societies and particularly in countries outside the "First World," depends on the removal of "unfreedoms," and consequently that freedom is both a constituent of development and its consequence. He develops this idea in contrast to traditional theories that measured development in terms of income, arguing that income is a poor measure 
of the quality of people's lives. He goes on to advance the idea that free agency is a prerequisite for development rather than the generation of wealth, as the traditional view of development had maintained. For Sen, to have a capacity is to have the resources and opportunity to achieve some self-set goal. A functioning is an achievement that realises a person's capabilities- it is what one actually does with a capacity one has. So every person has a capability set which contains alternative combinations of functionings. The measure of a person's freedom is defined by her capability set. What particular functions we value Sen leaves to "public understanding," discussion and the workings of democratic institutions.

In his book Resources, Values and Development, although he provides further examples of intrinsically valuable capabilities such as being able to live long, escape avoidable morbidity, be well nourished, be able to read, write and communicate, take part in literary and scientific pursuits and so forth (Sen, 1984: 497), he at the same time refuses to endorse a unique list of capabilities as objectively correct for practical and strategic reasons (Sen, 1993: 47). Instead he has argued that the selection and weighting of capabilities depend on personal value judgments - which are partly influenced by the nature and purpose of the evaluative exercise. That aside, some commentators have praised him, pointing out that one of the chief strengths of his framework is that it is flexible enough and exhibits a considerable degree of internal pluralism, which allows researchers to develop and apply it in many different ways (Sabina Alkire, 2002: 8-11 and 28-30). Sen himself has also indicated that the Capabilities framework can be used to assess individual advantage in a range of different spaces. For example, the assessment of poverty might involve concentrating on a relatively small sub-set of basic capabilities.

Today the Capabilities framework continues to enjoy ostensible influence on the United Nations Development Programme. Most prominently, it provides the theoretical foundation for the development of the Human Development Index, which is a composite index of a country's performance in the dimension of income, education, and health. In Africa, as is the case elsewhere in the developing world, it has become an important policy measure of a country's level of development that is also increasingly used as the basis for aid allocation. In the 2000 report (UNDP, 2000: ch. 1), for example, Sen literally stamped his signature in the document advancing his argument that the process of human development is the enhancement of human capabilities. The established discourse evident in other parts of the report went on to argue that human development and the reduction of poverty require economic growth, not human empowerment. Poor countries, the report supposed, should avail themselves of the opportunities that capitalist globalization can provide. In later chapters of the Human Development Report 2000 the term 'human capital' was 
insinuated as if it were a synonym for Sen's notion of human capabilities.

That said, British economist Sir Anthony Barns Atkinson has deflated Sen's Capabilities bubble by summing it up in two different ways. Sir Atkinson pointed out that it is only concerned with the actual chosen functioning, or with the options that a person has the capability set (Sen and Foster, 1997). In illustration, Sir Atkinson goes on to give two examples of two people who are starving, one of whom lacks food, the other of whom is starving out of choice on account of religious beliefs. Sir Atkinson then argues that evaluation in terms of actual functioning (i.e starvation in both cases) is closer to traditional welfare economics, being concerned with outcomes, but this does not capture the difference between the two people, which is that the second person could have made a different choice. The options approach raises in turn the issue as to how we evaluate the set of options: the degree of freedom of choice (Atkinson, 1998).

Despite its heuristic value, the foundations of the capabilities concept are essentially liberal. It therefore elides the fundamental and inherent contradictions of capitalism. As such, the concept of its 'equality' at a philosophical level and the meaning of equality in practice especially in Africa, continue to exhibit far and wide divergences especially in matters pertaining poverty and social justice. The mainstream understanding of the concept tends to dichotomise different understandings of justice without establishing coherent interlinkages and unities between them. This is especially so when it comes to the understanding of political and economic rights and to what extent principles of 'justice' could be said to exist between them. Nabudere has pointed out that the main reason behind the dichotomisation has been the attempt to impose the concept of 'justice,' as understood by Amartya Sen in Freedom as Development, which emerged in different historical and cultural contexts on different historical and cultural contexts without a hermeneutic dialogue (Nabudere, 2012: 6).

One of the greatest lessons of hermeneutics is that understanding is not only something that happens when people read texts or even when they consciously strive to gain intellectual access to social phenomena, but understanding happens all of the time in the life of all human beings (Paul Ricoeur 1986: 83-111). Understanding is part of the very fibre of human existence. It is a much larger phenomenon than a mental activity of conscious thinking - the latter is only a derived form of understanding. Understanding is most of the time and most originally situated on the pre-reflective level of human situatedness and interaction with the surroundings. 


\section{Traditional African Thought}

African society, for instance, continues to suffer a rapture of crisis of thought and culture as a result of the encounter with Rawls liberalism and the manifestations of a capabilities mindset which centers on individualism. In liberalism it is the individual, considered as an entity, who matters. Therefore, anything associated with individuals - their rights, for example, must be a priority, and respected and cherished. African thought, on the other hand, respects individuality but abhors individualism. This attitude arises from the understanding that people are bounded to each other in a web of life. Since people are interconnected by life, what affects one affects all - we are many yet one. For the African, it is respect for life and community that is a priority. South African philosopher Mogobe Ramose has termed this African way of life as the foundation of the Ubuntu philosophy (Ramose, 2003: 382).

Traditional African thought defines personhood in terms of wholeness. The African concept of a person as wholeness does not deny human individuality as what French scholar Michel Foucault termed as an "ontological fact", as an analytic finitude but ascribes ontological primacy to the community through which the human individual comes to know both himself and the world around him. On this reasoning, it can be said that there is a greater wholeness to which the single individual person belongs though in themselves, individuals must be seen as partial wholes (Foucault, 1970: 315). Therefore, the idea of holism is the starting point of the concept of a person. Professor Ramose has argued that consequently, the human person in African thought is definable in terms of a single characteristic to the exclusion of everything else. Thus the derivative concept of a person is apparently alien to traditional African thought. There is a difference between the holistic and the individualistic (derivative) conception of a person. The former accords primacy to wholeness while the latter emphasizes and accords primacy to the individualistic [partiality] conception (Ramose, 2005: 57).

\section{How Equality Status is Acquired}

In his 1984 article Person and Community in African traditional Thought, Nigerian Poet Ifeanyi Menkiti points out further that the African view of man denied that person can be defined by focusing on physical or psychological characteristics of the lone individual. Rather, man is defined of the communal world takes precedence over the reality of individual life histories, whatever they maybe. Professor Menkiti stresses that this primacy is meant to apply not only ontologically, but also in regards to epistemic accessibility. It is rootedness in an ongoing community that the individual also comes to know himself as a durable, more or less permanent fact of the world 
(Mentikiti I, 1984: 171-172). In a word, traditional African thought emphasizes the primacy of the greater environing wholeness over that of human individuality.

Professor Ramose has made a conclusion that as far as the African world in concerned, human individuality is not a sufficient condition for being a person. According to Ramose, in order to be a person, the human individual must, according to traditional African thought, go through various community prescribed stages, and be part of a certain ceremonies and rituals. Only at the completion of all prescribed stages does the human individual acquire the status of a person. Prior to this, the individual is regarded as "it" to show that he or she is not yet incorporated into the body of persons.

In traditional African thought personhood is, therefore, acquired and not merely established by virtue of the fact of being a human. Like personhood, parenthood in traditional African thought is not established merely by the fact that a female being has given birth to a human being, rather "it is through an imbeleko sacrifice that social parenthood is established. At the same time the Imbeleko sacrifice to the ancestors establishes social babyhood as well (Ramose, 2005: 58)

Ramose's examples goes to show that personhood in traditional African thought, whatever angle it is looked at, is acquired. As such, it is during the process of attainment, that the community plays a crucial role as a catalyst and prescriber or norms, rights, entitlements that in turn informs how equality is conceived and perceived.

Connectively, from the African context, if we consider the revolutionary Enlightenment objectives of egalité (equality), liberté (freedom), fraternité (solidarity), Sen's Capabilities approach to equality is framed in terms of freedom, but not solidarity. It is a liberal- individualist approach and while ethical individualism need not necessarily imply methodological individualism (Burchardt, 2006) the priority is individual liberty, not social solidarity; the freedom to choose, not the need to belong. In the space of Capabilities the individual is one step removed; she is objectively distanced from the relations of power within which her identity and her life chances must be constituted. Within the space of capabilities there are three major issues which the individual cannot readily see and which are seldom clearly discussed. First and in any event, human beings cannot be free from their dependency upon other human beings (Dean, 2009: 267). Second and third, under capitalist social relations of production, individuals can be free neither from 
hegemonic controls over their participation in the public realm, nor from the direct or indirect consequences of the exploitation of human labour.

\section{Michel Foucault}

We now turn out attention on Michel Foucault, the French philosopher whom until his death in 1984 was professor of History of Systems of Thought at the prestigious College de France. Foucault once described by a noted Frankfurt philosopher Jurgen Habermas as "a scholar striving for objectivity...and... the political vitality of the vulnerable, subjectively excitable, morally sensitive intellectual," (Murphy, 1990: 126) was in a word, much like Nabudere one of the greatest thinkers of the second half of the 20th century. For us, the novelty that connects Nabudere and Foucault is their recognition of the imbrications of freedom and power. For both of these thinkers, freedom is no longer conceived as the absence of constraint, but as the utilization of the power which circulates in all relations, not least repressive ones, and which is productive as much as it is constraining. As such, the discussions of Foucault's political thought and Nabudere's restorative epistemology of Afrikology forces one to shift sites from the distinction between freedom and constraint, to the distinction between freedom-as-power and domination.

\section{Freedom as Power}

In a 1983 interview with Paul Rabinow discussing Space, Power and Knowledge Foucault argued that material changes cannot be used to explain changes in subjectivity. He pointed out that, for instance, when in the Middle Ages, Chimneys were first walled and placed inside, rather than outside, houses and interpersonal relations were also transformed. New interactions flourished around the Chimneys. "But the building of Chimneys is not enough to explain these changes - if, for instance different discourses and values had been circulating at the times then Chimneys would have produced different kinds of changes."

Generalizing from this point of view, Foucault's was arguing that highly valued abstract words such as 'liberty' and 'rationality' in the Western world, refer neither simply to ideas nor to practices but to sets of complex exchanges between the two. Pointing out further that, 'practices' of liberty and reason have been a much neglected sphere by social and cultural historians. This line of thought has an important consequence. It means, in a way, that community leaders and other social managers cannot guarantee that their input will secure liberty or rationality. Foucault was convinced that what mattered was the fit between the material 
reorganization of space, life-practices, values and discourses. Only if the fit is right will social managers be able to augment what Foucault called "practices of liberty". In this light, Foucault argued that scholars had a particular function to play when society was being modified and rationalized by managers and experts; they are to remain critical of nostalgias, utopian and overtly abstract thought. Foucault concluded his thought while responding to another question posed by Paul Rabinow, who had asked whether Foucault saw architectural projects as forces of liberation or resistance, to which he replied -

"I do not think that there is anything that is functionally- by its very nature -absolutely liberating. Liberty is a practice. So there may, in fact, always be a certain number of projects whose aim is to modify some constraints, to loosen, or even to break them, but none of these projects can, simply by its nature, assure that people will have liberty automatically, that it will be established by the project itself. The liberty of men is never assured by the institutions and laws that are intended to guarantee them. This is why almost all of these laws and institutions are quite capable of being turned around. Not because they are ambiguous, but simply because 'liberty' is what must be exercised".

When we consider the problem of self-determination in this light, a more complex picture of Foucault's approach to freedom emerges, with potentially interesting implications for the relevance of Foucault's thought to questions of equality and social justice. I have felt it profitable to feature his views on freedom for purposes of highlighting the complexity involved in Nabudere's own views on freedoms and the subsequent role that the Afrikology undertakes to defend and advance them. Foucault, as does Nabudere, seems to be urging us to be critical in our analysis and vigilant of our institutions. As one writer has put it, "Foucault taught us to always beware of the possibilities that our own institutional arrangements will encourage the rise of new destructive forces inimical to the possibilities of our being free" (Dumm, 1996: 153).

Given this more intricate account of power, Foucault's political philosophy is widely thought to begin with the assumption that a subtler grasp of the forms of social control that constrain and shape the subject empowers the subject to resist these constraints more effectively. We learn from Foucault that the interrogation of power should not conclude with government, that is, with systems of law and legal or extra-legal forms of repression, but must extend to 'governmentality', meaning the modes of organizing knowledge and disciplining bodies that state apparatuses 
may co-opt and employ in the production of inequalities and social injustices. Professor Nabudere's epistemological reasoning on Afrikology seems to be in concert with Foucault's ontological premise in that they both characterize ethics and equality as reflexive practices of freedom. Their ideas are primarily fuelled by an understanding that social justice reasoning is not or were not merely an economist or lawyer's desideratum; in that they were also a prerequisite for the legitimacy of the 'capable community'. In order to comprehend such a position, it is important to depart from the single measure of social (in)justice confined to Capabilities' Gini coefficient envelop. This consideration is central in our understanding of the social justice scene in the African context. Inspired by John Rawls's overtly normative liberal approach, Sen's Capabilities approach has effectively argued that the best way for governments to help the poor is to assign public resources to education and health services for them. Education and health are said to be keys to ending poverty because they enhance the market value of what the poor have to sell: themselves.

Professor Dean has indeed cautioned that it should no longer be viable to sing along the Capabilities bandwagon in spite of the official national and international agencies adoption of the language of capabilities while studiously ignoring key drivers of inequality and poverty. For all its attractions, the concept is in itself constrained. The 'space of capabilities' is abstracted from the 'space of commodities' and the 'space of functionings' in ways that necessarily constrain the critical purchase of the concept (Hartley Dean, 2009: 266). Elsewhere, South African scholar Vivienne Taylor, in her contribution to discourses on social justice in Africa, has argued that economic growth alone cannot structurally address issues of poverty, exclusion, and inequity in Africa. Strategies to ensure human development and social justice are also required, and they are required now, she argues, even in a context where a democratic deficit may mute demands for social justice (Taylor, 2012).

Professor Taylor has further pointed out in her study of East Africa that a critical analysis of the region's economic growth and the level of human development reflect the disjuncture between economic growth as an indication of development and the conditions of the people. "In the period between 2000 and 2010, East Africa's economy more than doubled in real terms, growing from US\$32 billion to US $\$ 79$ billion. If Rwanda continues to grow at an average of 7.7 percent, Tanzania at 6.8 percent, and Uganda at 7.2 percent, and Kenya, currently at 3.7 percent accelerates, these countries are set to reach middle-income status in another decade, that is, by 2022" (Taylor 2012: 13). That said, there is no evidence that the economic growth is commensurate to the quest for social justice in the region. 
Furthermore, as pointed out by the late French sociologist Pirre Bourdier, though it may have an application within critical sociological analysis (Bourdieu, 1997: 46-58), as a metaphor in policy discourse the concept of human capital takes on a distinctly reductive economistic meaning: individuals are constituted as actual or potential economic actors. Whether it represents a wilful corruption or a misunderstanding of the idea of human capabilities, the human capital approach continues to reflect essential elements of the economic and political orthodoxy once dubbed the 'Washington Consensus' - a consensus by which the ability of the poor to 'succeed' is construed too readily as a property or characteristic of individuals. Even within the context of the targets set by the Millennium Development Goals (UNDP, 2003) the recipe for tackling world poverty still favours the liberalization of trade and financial markets, the privatization and deregulation of economic production, flexible labour markets, low public spending and taxation, and selective social 'safety nets'.

\section{Conclusion}

Conclusively, Sen's capability framework continues to occupy a significant portion in the social sciences and humanities academic circuits. However, Capabilities are not the same as abilities. The term refers not simply to what people are able to do but to their freedom to lead the kind of lives they value, and have reason to value. As South African writer Paul Voice has noted elsewhere, what we can take from Sen is that whatever capacity is being targeted, the focus of attention is on individuals and their particular resources and opportunities. It is not possible to think of having a capacity in a merely formal sense. Having a capacity means that it can be exercised by a particular individual. Having a "right to participate in the political process" without the corresponding capacity in the robust sense that Sen means it - having both sufficient resources and genuine opportunities makes no sense. Thus the distinction between liberty and the "worth of liberty" likewise makes no sense (Paul Voice, 2004: 205). Indeed the aporia at the heart of the capability concept is the notion of the things to do and be that the individual values and has reason to value. By implication, the individual must have 'good' reason to value such things. But the question of "who is to determine what constitutes good reason" is largely left unanswered.

Capabilities framework as a theory of social justice is grounded in the cosmopolitanism philosophy which believes in global justice without consideration of local cultural boundaries of human beings, for instance, the moral standing of African communities. Therefore, it has been victimizing to those who do not conform to its list of expectations. Over time Africa has been the subject of much 
focus because of its location in the global economy and its 'peripheral' geopolitical status. It's social, economic, and political context has as such been shaped by multiple forces external and internal to the continent.

Unlike Sen's Capabilities which promotes the supremacy of the individual, we have attempted to demonstrate how Nabudere's Afrikology centred on African hermeneutics, promotes equity and fairness. The historical experience, which African communities have gone through under colonialism and post-colonialism proves that Africans have consistently used their cultural heritage to survive the impositions of colonialism under different guises. Although the colonialists were able to use some aspects of African customs and traditions in order to enforce their colonial rule, this did not succeed in subduing the people. One significant contribution of Afrikology to the study of social justice, as we have demonstrated, is its persuasion to the academic understanding of social change in Africa is its capacity to explode often victimizing approaches in exchange for a much more balanced understanding of the local processes at work in Africa.

This is what Guinea-Bissau's Amilcar Cabral called the "practice of freedom" resulting from emancipation where the practice of freedom becomes the lived actuality of the formerly colonised people since it represents the triumph of the people over colonialism and the tyrannies of post-colonial rule inherited from it. To this end, emancipatory knowledge in the African context aims at two things: firstly, to identify problems that impact negatively on peoples' lives arising out of the colonial and post-colonial experience; secondly, to identify tools, which can resolve those problems and contradictions in a positive manner. In short, emancipatory knowledge offered through the restorative epistemology of Afrikology is a liberating and humanising process (Nabudere, 2004) reconciling "man with himself." This applies to all human action and Afrikology therefore contributes to a new worldview that can enable humanity to move beyond the constraints of the modern crisis of reason to a new world in which development learning structures play a constructive rather than a destructive role.

\section{References}

Arif, N.M., 2002. The Disenchantment of Political Development: Epistemes, Cultures, and Policies. University Press of America, Maryland.

Alkire, S. 2002. Valuing Freedoms: Sen.s Capability Approach and Poverty Reduction. Oxford:

Oxford University Press.

Atkinson, A.B., 1998. The Contributions of Sen to Welfare Economics, Oxford University Press, Oxford. Available at www.nuff.ox.ac.uk/users/atkinson/sen1998.pdf (accessed 12 October 2015). 
Bourdieu, P. 1997. 'The Forms of Capital', pp. 46-58 in A. Halsey, H. Lauder, P. Brown and A. Wells (eds) Education, Culture, Economy, Society. Oxford: Oxford University Press.

Burchardt, T. 2006. 'Foundations for Measuring Equality: A Discussion Paper for the Equalities Review', CASE paper 111. London: CASE/STICERD.

Dean, H., 2010. From Work to Welfare? Reconstructing the Liberal Discourse, Social Policy in the Times of Change, Social Policy Association, University of Lincoln.

Dean, H., 2011. Critiquing Capabilities - The Distractions of a Beguiling Concept, Critical Social Policy, Vol. 29, No. 2.

Dean, H. and Rogers, R., 2004. Popular Discourse and the Ethical Deficiency of 'Third Way', Journal of Social Policy, Vol. 32, No. 3.

Doussou. F.C. 1997. Writing and Oral tradition in the Transmission of Knowledge. In Hountondji P. ed. 1997. Endogenous Research Trails. Oxford. CODESRIA.

Dumm, T.L. 1996. Michel Foucault and the Politics of Freedom. London: Sage.

Foucault, M., 1970. The Order of Things, Laing R.D, Tavistock Publications, London.

Foucault, M., 1999. Space, Power and Knowledge, The Cultural Studies Reader, Ch. 10., Simon During (ed), Routledge, 2nd Ed.

Hoppers C.A. 2008b. Cultural Diversity, Traditions and Modernities: Complexities and Opportunities in the C21st century. In UNESCO World Report on Cultural Diversity. Paris, UNESCO.

Hountondji P. 1997. Introduction. In Hountondji P. ed.1997. Endogenous Research Trails. Oxford. CODESRIA.

Menkiti, I., 1984. Person and Community in Traditional African Thought, African Philosophy, Wright, R.A., (Ed.) New York.

Mozaffar Qizilbash. 2013. On Capability and the Good Life: Theoretical Debates and their Practical Implications, Philosophy and Public policy Quarterly, Vol. 31, No 2.

Murphy, W., T., 1990. Fowcault: Rationality against reason and History in Reason and History, Phillip Windsor(ed), Licester University Press.

Nabudere, D.W., 2012. Afrikology and Transdisciplinarity: A Restorative Epistemology, AISA, South Africa.

Nabudere, D., 2011. Afrikology: Philosophy and Wholeness, Pretoria: Africa Institute of South Africa.

Nabudere, D. W. 2004. Africa's First World War: Mineral Wealth, Conflict and War in the Great Lakes Region, Occasional Paper series, Volume 8, Number 1, 2004, Pretoria.

Rabinow P., 1984. The Foucault Reader. An Introduction to Foucault's Thought. New York. Pantheon Books. 
Ramose, M. 2003. 'Globalisation and Ubuntu', pp. 626-50 in P. Coetzee and A. Roux (eds) The African Philosophy Reader. London: Routledge.

Ramose, M. 2005. African Philosophy Through Ubuntu, Mond Books Publishers, Harare, Zimbabwe.

Rawls, J. 1972. A Theory of Justice. Oxford: Oxford University Press.

Ricoeur, P., 1986. From Text to Action: Essays in Hermeneutics II, trans. Kathleen Blamey and John

B. Thompson, Evanston: Northwestern University Press, 1991 (1986).

Sen, Amartya K. 1993. Capability and Well-being. in Martha C. Nussbaum and Amartya K. Sen (eds), The Quality of Life, Oxford: Clarendon Press.

Sen, Amartya K. 1984. Resources, Values and Development. Oxford: Basil Blackwell.

Sen, A. 1985. Commodities and Capabilities. Amsterdam: Elsevier.

Sen, A. 1999. Development as Freedom. Oxford: Oxford University Press.

Sen, A. 2005. 'Human Rights and Capabilities', Journal of Human Development. Vol. 6, No. 2.

Taylor, Viviene., 2012. Social Justice: Reframing the "Social” in Critical Discourses in Africa, in Sarah Tange’s (ed.) African Perspectives on Social Justice, Friedrich -Ebert-Stiftung, Uganda.

United Nations Development Programme (UNDP). 2000. Human Development Report 2000. Oxford: Oxford University Press.

United Nations Development Programme (UNDP). 2003. Human Development Report 2003 Millennium Development Goals: A Compact among Nations to End Human Poverty. New York: Oxford University Press.

Voice, Paul. 2004. The True Confessions of a White Rawlsian Liberal: An Argument for a Capacities Approach to Democratic Legitimacy. South African Journal of Philosophy Vol. 23, Issue 2.

Wanda, R.E. 2013. Afrikology and Community: restorative Cultural Practices in East Africa, Journal of Pan African Studies, Vol. 6., No. 6. 